\title{
Estimating age of Brazilians using the methods of Demirjian and Nicodemo, Moraes and Médici: A comparative analysis
}

\author{
Ricarda Duarte da Silva*, Marcos André Duarte da Silva, Aline Yumi Uezono, \\ Simone Borges Braga dos Santos Queiroz, Rogério Nogueira de Oliveira \\ Department of Social Dentistry, University of São Paulo, São Paulo, Brazil; *Corresponding Author: ricardads@ig.com.br
}

Received 3 April 2013; revised 3 May 2013; accepted 10 May 2013

Copyright (C) 2013 Ricarda Duarte da Silva et al. This is an open access article distributed under the Creative Commons Attribution License, which permits unrestricted use, distribution, and reproduction in any medium, provided the original work is properly cited.

\section{ABSTRACT}

This study proposed to evaluate the precision of Nicodemo, Moraes and Médici method and the method proposed by Demirjian and compare both methodologies in relation to the efficiency and applicability in the Brazilian population. The sample consisted of $\mathbf{1 2 4}$ panoramic radiographs of subjects in the age group from 7 to 16 years old, 66 patients female and 58 male. For the comparison of the genders in relation to the average percentage difference, the t-Student test was considered. In average the method of Nicodemo, Moraes and Médici presented for the female gender an estimated result $14.7 \%$ lower than the real age. For the male gender the estimative obtained was that for each year of variation of the real age the method of Nicodemo estimates a variation of 0.48 years, with a confidence interval of $95 \%$ given by $(0.43 ; 0.54)$. For the method of Demirjian the result was that for each year of variation of the real age the method of Demirjian estimates a variation of 1.00 year, with a confidence interval of $95 \%$ given by $(0.85$; 1.15) for the male gender and 0.96 years, with a confidence interval of $95 \%$ given by $(0.84 ; 1.08)$ for the female gender. It is concluded that the Method of Nicodemo, Moraes and Médici tends to underestimate the real age and that as the real age increases this underestimate becomes higher. Now, the method of Demirjian tends to overestimate the real age in $\mathbf{8 . 2}$ months for the male gender and in $\mathbf{7 . 1}$ for the female one in average.

Keywords: Dentistry; Age Estimative; Forensic Dentistry; Forensics

\section{INTRODUCTION}

The term age represents the life stages of the human being, in other words, it is related to the development of the individual's maturation [1]. The analysis of the dental maturation stages, often, is the only viable alternative to obtain the chronological age of the individual [2-4]. During the transition period between the adolescence and the adulthood, biological variations in the growth and development of the dental roots and their different levels of maturation are observed [5,6]. It is still important to emphasize that the teeth are less susceptive to the pathologies, hormone and nutritional deficiencies that can affect greatly the bone development, being this way great age indicators [7-10].

The age estimation can be given through the dental clinical analysis and through the radiographic investigation of the dental elements. Different methods have been recommended to estimate the age through the dental development, among them we find Nicodemo, Moraes and Médici [11], which advocated for a chronology table of the permanent teeth mineralization, applied to Brazilians, once the foreigner methodology used to the age estimate through the chronological analysis of the permanent teeth mineralization was not applied to the Brazilian population. Additionally, Demirjian et al. [12] proposed a dental age evaluation method, through the use of dental development divided in eight very distinct mineralization stages to molars and premolars and six stages to incisors and canines.

In 1974, Nicodemo, Moraes and Médici [11], presented a representative chart of the mineralization of all the permanent teeth and determined eight development stages, being four stages to the crown and four to the root, described in the following way: 1) First mineralization evidence, 2) $1 / 3$ of the crown, 3) $2 / 3$ of the crown, 4) complete crown, 5) beginning of the root formation, 6) 
$1 / 3$ of the root, 7) $2 / 3$ of the root, and 8) $3 / 3$ of the root formed with apical closure (Figure 1). This table was elaborated based on the results obtained in three studies done by the authors [13-15].

For the use of the table of Nicodemo, Moraes and Médici [11], it is necessary to take a panoramic radiograph, from where the information of dental elements will be extracted, comparing the radiographic image of the teeth in formation with the design related to the eight mineralization stages. Then the chronological table of mineralization is applied, with the possibility of achieving very satisfactory results, mainly in groups of low chronological age (ages under 7), since these present a higher number of teeth that provide information for the analysis and also for the individual variations being less pronounced $[10,11]$.

The method of Demirjian et al., presented in 1973 [12] proposes to estimate the dental maturity and/or dental age through the dental development stages observed in each tooth. Demirjian provides guidelines for the use of the method saying that: the evaluation of the permanent mandibular teeth must follow the order-second molar, first molar, second premolar, first premolar, canine, side incisor and central incisor; all the teeth are evaluated in a scale from $\mathrm{A}$ to $\mathrm{H}$; the framing in each scale (from $\mathrm{A}$ to $\mathrm{H}$ ) follows the criteria described to each stage, comparing the teeth in the $\mathrm{x}$ ray with the diagrams; there are no absolute measures. A pair of divisors is enough for the comparison of the relative length (crown/root). The sum of the scores of the seven teeth can be converted directly in the dental age. It was emphasized that the maturity stages system is universal, however the conversion to the dental age depends on the population considered, it is still affirmed that the present method is applicable between the ages of 3 and 17 [12,16-22].

At the present time, to estimate the age in Brazilians, it has been recommended the use of the mineralization chronology table of the permanent teeth developed by Nicodemo, Moraes and Médici [11]. However, in heterogeneous populations all over the world there is a extensive use of the methodology proposed by Demirjian [12], so that, it is proposed with this study, the applica-
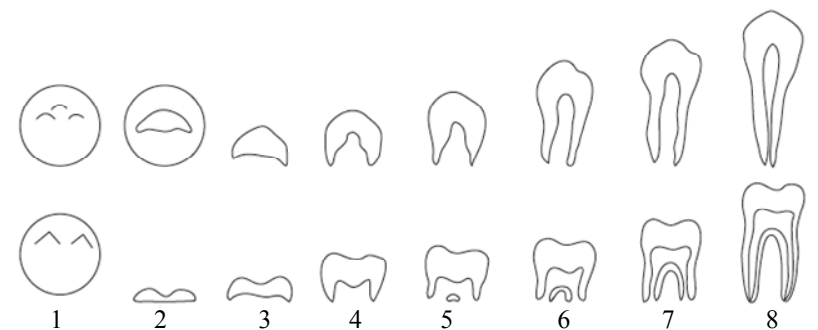

Figure 1. Stages of mineralization of the teeth on the mineralization chronology proposed by Nicodemo, Moraes and Medici Filho. tion of this methodology in Brazilian individuals in order to compare the results obtained with the table recommended by Nicodemo, Moraes and Médici [11] and to verify its efficiency and applicability in the Brazilian population.

\section{MATERIALS AND METHODS}

The initial sample will consist of 124 panoramic radiographs from the Dentistry College of the University of São Paulo, leucodermic subjects, in the age group from 7 to 16 years old, 66 patients of the female gender and 58 of the male gender. The age estimation of the sample was obtained through the method of Demirjian and through the method of Nicodemo, Moraes and Médici as described in the literature. For the radiographic interpretation, 3 operators were calibrated for both methods, this way a standardization of the radiographic analysis was obtained. The panoramic radiographs were numbered from 50 to 176 randomly. The data; age-years and months - and gender, were recorded in a form. The operators estimated the age of the sample firstly through the method of Demirjian and later through the method of Nicodemo, Moraes and Médici.

The method of Demirjian; the seven mandibular teeth, left side, in the following radiographic sequence: second molar, first molar, second premolar, first premolar, canine, side incisor and central incisor were analyzed and according to its root development, through comparison, it was attributed a stage to each tooth according to the eight stages proposed by Demirjian. Then it was attributed the value (score) to each phase according to the tables proposed by Demirjian, which take into consideration the gender. The values obtained were add and converted in age using the conversion table proposed by Demirjian.

The method of Nicodemo, Moraes and Médici; the radiographic images of the permanent teeth present in the panoramic radiographs with the eight development stages proposed by the authors were compared. Then it was applied the chronologic table of the permanent teeth mineralization among Brazilians proposed by the authors. It was obtained to each of the permanent teeth a score or value in months for the age. The most discrepant maximum and minimum values were eliminated when these existed. And then, it was determined, from the maximum and minimum values found, an age average of the individuals age in months.

The results obtained through the methodology of Demirjian were transformed in months and tabulated, as well as the results obtained through the method of Nicodemo, Moraes and Médici. In the statistical analysis for the evaluation of the estimated age variation of the different methods in relation to the real age variation it was considered the estimation of the angular coefficient 
through the linear regression model. For the evaluation of the different methods quality in the real age estimation, it was considered the Bland-Altman model, where for the evaluation of the bias between the estimated age and the real age, it was considered the test of Student for paired samples. For the estimation of the method error, it was considered the variance components model, with the estimation of the interclass correlation coefficient. Confidence intervals were constructed with $95 \%$ of confidence and values of $\mathrm{p}$ lower than 0.05 indicated statisticcal significance.

For the use of the radiographic data of the individual it was obtained together the Orthodontics department of the University of São Paulo the consent previously given, by the responsible ones, authorizing the use of the data to the purpose of researching.

\section{RESULTS}

For the method of Nicodemo, Moraes and Médici in all the age estimative, the average, the maximum and minimum and for both genders, it tested at first the null hypothesis that for each year of variation of the real age the method estimates a variation of one year, versus the alternative hypothesis that for each year of variation in the real age the method of Nicodemo estimates a different variation of one year. The result of the statistical test indicated the rejection of the null hypothesis $(p<0.001)$.

1) Evaluation of the age estimation through the method of Nicodemo, Moraes and Médici_-Average estimated age.

The estimative obtained for the male gender was that for each month of variation of the real age the method of Nicodemo, Moraes and Médici estimates a variation of 0.48 months, with a confidence interval of $95 \%$ given by $(0.43 ; 0.54)$. The method sub estimates the real age, increasing this sub estimation as the real increases (Figure 2).

The bias in the real age estimation depends on the age, as it can be observed in the figure below, where it can be observed that for higher ages the method tends to

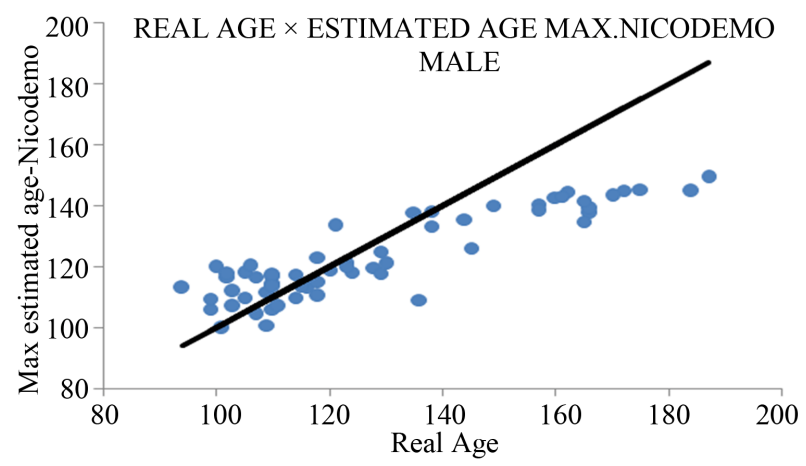

Figure 2. Comparison between the real age agaist the estimated average age through the method of Nicodemo, Moraes and Médici for the male gender. sub estimate the real age (Figure 3).

The estimative obtained with the female gender was that for each month of variation of the real age the method of Nicodemo estimates a variation of 0.41 months, with an confidence interval of $95 \%$ given by $(0.36 ; 0.45)$. The method sub estimates the real age, increasing this sub estimation as the real age increases (Figure 4).

The bias in the estimation of the real age depends on the age, as it can be observed in the figure below, where it can be observed that for higher ages the method tends to sub estimate the real age (Figure 5).

2) Evaluation of the age estimative through the method of Demirjian.

At first it was tested the null hypothesis that for each month of variation of the real age the Demirjian's method estimates a variation of one year, versus the alternative hypothesis that for each year of variation of the real age the Demirjian's method estimates a different variation of one year. The result of the statistical test indicated the non rejection of the null hypothesis for the male gender $(\mathrm{p}=0.979)$ and for the gender female $(\mathrm{p}=$ $0.517)$.

The Demirjian's method estimated a variation of 1.00

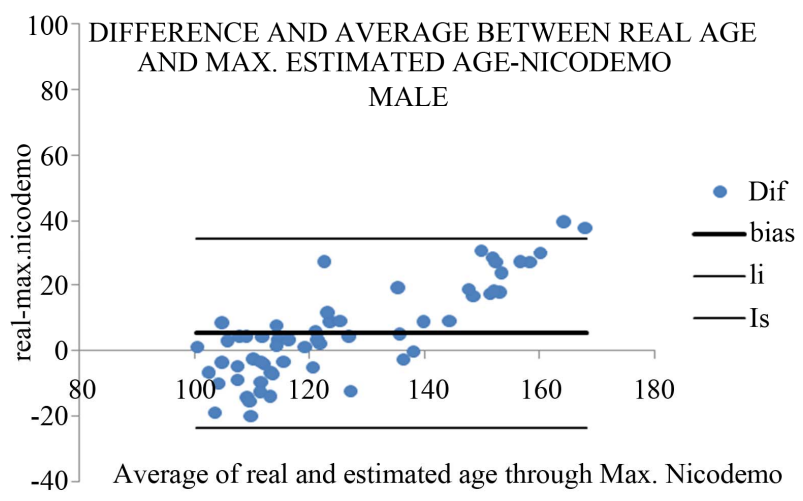

Figure 3. Difference between the real age and estimated average age through the method of Nicodemo, Moraes and Médici for the male gender.

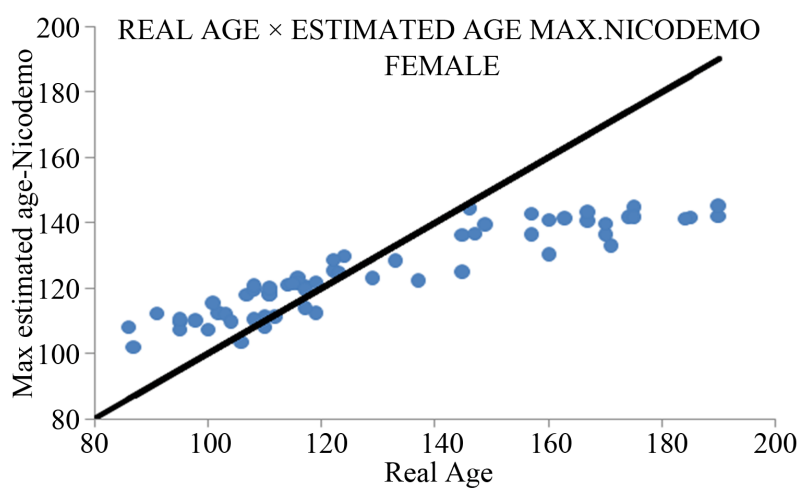

Figure 4. Comparison between the real age against the estimated average age through the method of Nicodemo, Moraes and Médici for the female gender. 


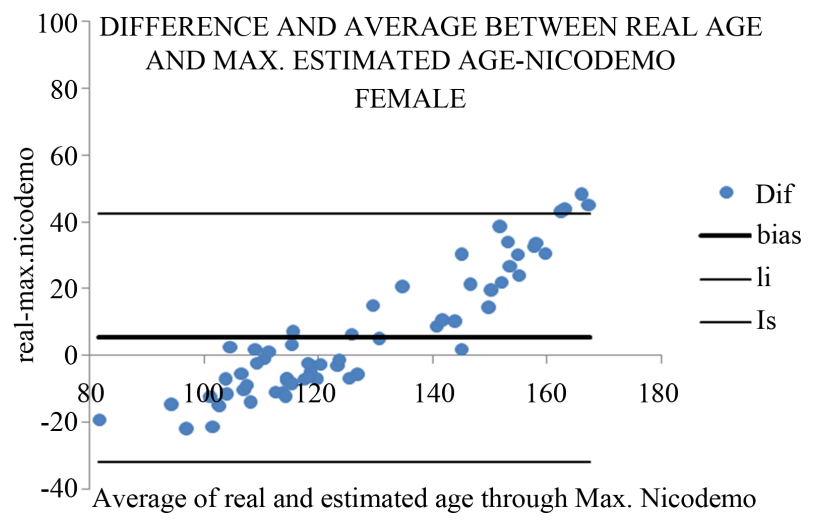

Figure 5. Difference between the real age and the estimated average age through the method of Nicodemo, Moraes and Médici for the female gender.

months, with a confidence interval of $95 \%$ given by $(0.85 ; 1.15)$ for each month of variation of the real age it for the male gender (Figure 6). And estimated a variation of 0.96 months, with a confidence interval of $95 \%$ given by $(0.84 ; 1.08)$ for the female gender (Figure 7). It indicates that the method estimates the variation of the real age in an adequate way. This result indicates that it is not rejected the hypothesis of parallelism in the relation between real age and estimated age through the method of Demirjian.

Defining the bias as it being the difference between the result of the real age and the estimated age through the method of Demirjian, it was tested the null hypothesis that the average bias is equal to 0 versus the alternative hypothesis that the bias differs from 0 .

The estimated bias for the male gender was of -8.2 with a confidence interval of $95 \%$ given by $(-11.74$; $-4.62)$. The result of the statistical test indicated the rejection of the null hypothesis in the significance level of $5 \%(\mathrm{p}<0.01)$, indicating that the hypothesis of absence of bias between the results of real age and estimated age through the method of Demirjian is rejected. These results indicate that in average the results of the real age are 8.20 months lower than the results of estimated age through Demirjian. The interval $(-11.74 ;-4.62)$ has $95 \%$ of chance of containing the real average difference (bias) (Figure 8).

For the female gender the estimated bias was -7.1 with a confidence interval of $95 \%$ given by $(-10.97$; $-3.31)$. The result of the statistical test indicated the rejection of the null hypothesis in the significance level of $5 \%(\mathrm{p}<0.01)$, indicating that the hypothesis of absence of bias between the results of real age and estimated age through the method of Demirjian is rejected. These results indicate that in average the results of the real age are 7.10 months lower than the results of the estimated age by Demirjian. The interval $(-10.97 ;-3.31)$ has $95 \%$ of chance of containing the real average difference (bias)

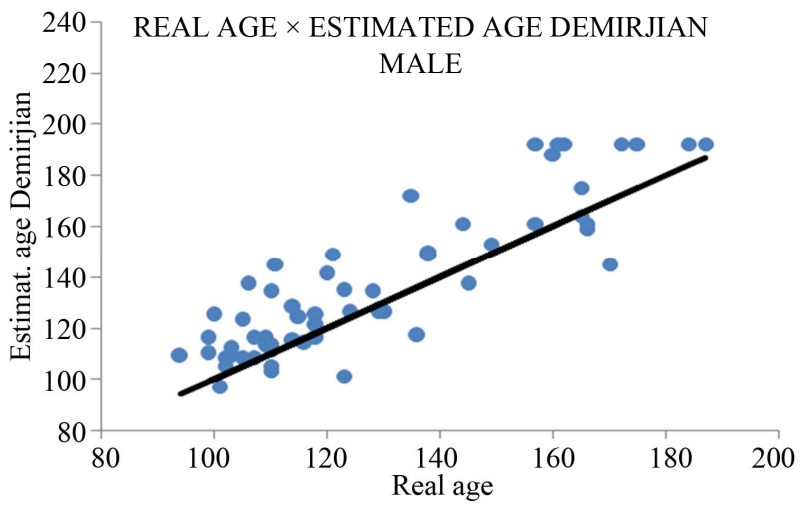

Figure 6. Real age against estimated age through the method of Demirjian for the male gender.

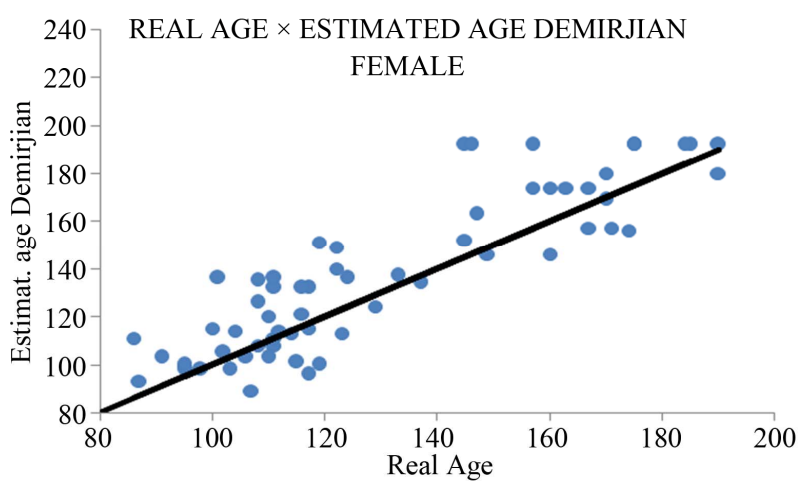

Figure 7. Real age and estimated age through the method of Demirjian for the female gender.

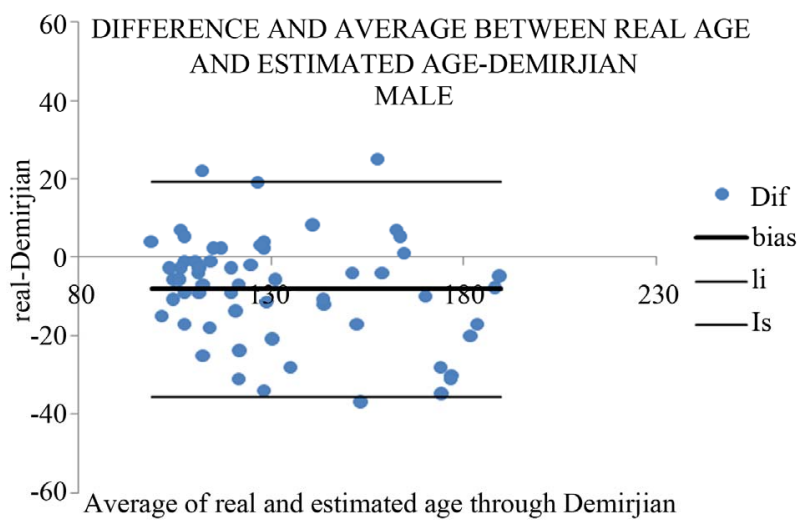

Figure 8. Average difference between the real age and the estimated age through the method of Demirjian for the male gender.

\section{(Figure 9).}

The diagram of dispersion with the average of both results and the difference between them is presented in the chart bellow, where it can be seen the concordance limits and the estimated bias.

3) Method's error.

For the method of Demirjian the estimated error for the method was corresponding to 5.29 months. The 


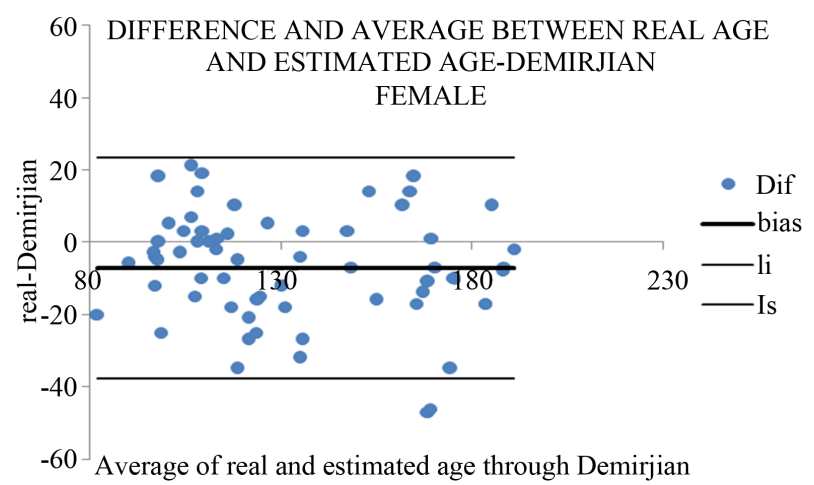

Figure 9. Average difference between the real age and the estimated age through the method of Demirjian for the female gender.

estimated intra-class correlation was equal to $89.58 \%$, indicating a good repeatability among the results of the evaluators. And for the method of Nicodemo Moraes and Médici the estimated error for this method was corresponding to 2.93 months. The estimated intra-class correlation was equal to $85.32 \%$, indicating a good repeatability among the results of the evaluators.

\section{DISCUSSION}

The studies developed by Nicodemo [13], Moraes [14] and Médici [15] which analyzed the mineralization chronology of the permanent teeth, demonstrated a tendency to the premature development of the permanent dentition in the Brazilian population due to the acceleration in the final stages when compared with the dental development tables of foreigner populations. It leads us to a conclusion that these tables would tend to overestimate the age when applied to the Brazilian population $[4,10,11]$. The present study confirmed this tendency of the age overestimate when applying the method of Demirjian et al. [12] in the Brazilian population, which is widely used and applied in heterogeneous populations all over the world [16,18-21]. However, when the method of Nicodemo, Moraes and Médici [11] is applied in the same population it was found an underestimate of the real age.

In the present study it was verified that for each month of variation of the real age the method of Nicodemo, Moraes and Médici [11] estimates a variation of 0.48 months, with a confidence interval of $95 \%$ given by $(0.43 ; 0.54)$ for the male gender and 0.41 months, with a confidence interval of $95 \%$ given by $(0.36 ; 0.45)$ for the female gender. This sub estimation occurs equally for the estimated average age, for the estimated minimum age or for the estimated maximum age through the method of Nicodemo, Moraes and Médici [11]. Now, the estimative obtained through the method of Demirjian et al. [12] was that for each month of variation of the real age the method estimates a variation of 1.00 months, with a con- fidence interval of $95 \%$ given by $(0.85 ; 1.15)$ for the male gender and 0.96 months, with a confidence interval of $95 \%$ given by $(0.84 ; 1.08)$ for the female gender. It can be said that the method of Demirjian et al. [12] estimates the variation of the real age in an adequate way for both genders. As Bagherpour et al. [18] reported that the method is appropriate for the Iranian population studied mainly for the age group from 9 to 13 years old. Despite that they observed in the Iranian population a super estimation of the method in average of 0.34 years for the boys and 0.25 years for the girls. While some authors verified a super consistent estimation of the method of Demirjian et al. [12], as Staaf, Mornstad and Welander [22], by estimating the age of 541 Swedish children, with ages between $5.5-14.5$ they observed a super estimation of the age in 10 months for both genders when the method of Demirjian et al. [12] was used. Willems et al. [19] in the Belgian population, in 2001, found an average of 0.5 years for the boys and 0.6 years for the girls and the worst results were in the age from 9 to 10 for the boys and from 9 to 11 for the girls. Blenkin and Evans [20] in a population from Sydnei, Australia, report a consistent super estimation of the chronological age in children under 14 years old, with an average of 0.99 years. And at last, for Davis and Hägg [21] the method of Demirjian could not be used to estimate accurately the chronological age of the Chinese children in the age group from 5 to 7 once they found an average difference between the dental age and the real age in the Chinese children of 11 months for the boys and of 7 months for the girls. The confidence interval of $95 \%$ was of around $+/-15$ months in both genders.

In this study the percentage of difference between the estimated and the observed result for each one of the methods in relation to the different ages show that the higher the real age the higher is the sub estimation of the method of Nicodemo, Moraes and Médici [11], for both genders. It can be perceived an increase of the error in the method of Nicodemo, Moraes and Médici [11] with the increase of the real age. Now, in the method of Demirjian et al. [12] there is some stability in the (absolute) error with an average estimative of age corresponding to 6.1 months more, independently from the real age in the female gender, while in the male gender this stability of the error was of 10.5 months more, independently from the real age.

\section{CONCLUSION}

The method of Nicodemo, Moraes and Médici [11] tends to underestimate the real age and as the real age increases, higher becomes this underestimate. While, the method of Demirjian et al. [12] presents a tendency to overestimate the real age in 8.2 months to the male gender and in 7.1 months to the female gender independ- 
ently from the real age. So, it was possible to conclude that the Method of Demirjian et al. [12] was appropriate to estimate the age in the population studied and when compared with the method of Nicodemo, Moraes and Médici it was more precise once it permits to identify an absolute mistake.

\section{REFERENCES}

[1] Willem, G. (2001) A review of the most commonly used dental age estimation techniques. The Journal of Forensic Odonto-Stomatology, 19, 9-17.

[2] Schmeling, A., Reisinger, W., Geserick, G. and Olze, A. (2006) Age estimation of unaccompanied minors Part I. General considerations. Forensic Science International, 159, S61-S64. doi:10.1016/j.forsciint.2006.02.017

[3] Daruje, R.J. (2000) Computerized facial reconstruction and their importance in identification. Ph.D. Thesis, State University of Campinas/FOP, Piracicaba.

[4] Santoro, V., De Donno, A., Marrone, M., Campobasso, C.P. and Introna, F. (2009) Forensic age estimation of living individuals: A retrospective analysis. Forensic Science International, 193, 129.e1-129.e4.

[5] Glaser, I. and Hunt Jr., E.E. (1955) The Permanent mandibular first molar its calcification eruption and decay. American Journal of Physical Anthropology, 13, 253-281. doi:10.1002/ajpa.1330130206

[6] Nolla, C.M. (1960) The development of permanent teeth. Journal of Dentistry for Children, 27, 254-266.

[7] Marcondes, E., Rummel, A. and Schuartsman, S. (1965) Determination of bone age and dental, by radiographic examination in children from low socio-economic status. Journal of the Faculty of Dentistry, University of São Paulo, 3, 185-191.

[8] Krogman, W.M. (1968) Biological timing and dentofacial complex. Journal of Dentistry for Children, 35, 175-184.

[9] Hagg, U. and Matsson, L. (1985) Dental maturity as an indicator of chronological age: The accuracy and precision of three methods. European Journal of Orthodontics, 7, 25-34. doi:10.1093/ejo/7.1.25

[10] Cardozo, H.F. and Silva, M. (1997) Age estimation by examining the teeth. In: Silva, M., Ed., Compendium of Legal Dentistry, Medsi, São Paulo, 125-148.

[11] Nicodemo, R.A., Moraes, L.C. and Médici, E. (1974) Chronological table of mineralization of permanent teeth among Brazilians. Journal of the Faculty of Dentistry, 3,
$55-56$.

[12] Demirjian, A., Goldstein, A.H. and Tanner, J.M. (1973) A new systems of dental age assessment. Human Biology, 45, 211-227.

[13] Nicodemo, R.A. (1967) Contribution to the study of the chronology of mineralization of third molars, radiographic method in Caucasian Brazilians residing in the Paraíba Valley. Ph.D. Thesis, University of São Paulo, São José dos Campos.

[14] Moraes, L.C. (1973) Chronology of mineralization of incisors and first permanent molars, radiographic method. Ph.D. Thesis, University of São Paulo, São José dos Campos.

[15] Médici Filho, E. (1973) Chronology of mineralization of canines, premolars and second molars among Brazilian whites, radiographic method. Ph.D. Thesis, University of São Paulo, São José dos Campos.

[16] Demirjian, A. and Goldstein, H. (1976) New systems for dental maturity based on seen and four teeth. Annals of Human Biology, 3, 411-421. doi:10.1080/03014467600001671

[17] Blenkin, M. (2009) Forensic odontology and age estimation. VDM Verlag Dr. Muller aktiengesellshHaft \& CO. $\mathrm{KG}$, Saarbrücken.

[18] Bagherpour, A., Imanimoghaddam, M., Bagherpour, M.R. and Einolghozati, M. (2010) Dental age assessment among Iranian children aged 6 - 13 years using the Demirjian method. Forensic Science International, 197, 121e1$121 \mathrm{e} 4$.

[19] Willems, G., Van Olmen Spiessens, A.B. and Carels, C. (2001) Dental age estimation in Belgian children: Demirjian's technique revisited. Journal of Forensic Sciences, 46, 893-895.

[20] Blenkin, M.R.B. and Evans, W. (2010) Age estimation from the teeth using a modified Demirjian system. Journal of Forensic Sciences, 55, 1504-1508. doi:10.1111/j.1556-4029.2010.01491.x

[21] Davis, P.G. and Hägg, U. (1994) The accuracy and precision of the Demirjian system when used for age determination in Chinese children. Swedish Dental Journal, 18, 113-116.

[22] Staff, V., Mornstad, H. and Welander, U. (1991) Age estimation based on tooth development; a test of reliability and vahdity. Scandinavian Journal of Dental Research, 99, 281-286. 